\title{
Comparison of Mental Health Status between Two Periods during Coronavirus Disease 2019 Pandemic in Iranian Adult Population
}

Arash Mani ${ }^{1}$, Alireza Estedlal ${ }^{2}$, Ali Akbary ${ }^{3}$, Taraneh Estedlal ${ }^{4}$, Sara Ouladinejad-Rodbali², Saeed Shahabi ${ }^{2}$, Seyede-

Zahra Ghaemi ${ }^{2}$, Leila Zarei ${ }^{2}$, Seyed-Taghi Heydari ${ }^{2 \bowtie}$, Kamran Bagheri-Lankarani ${ }^{2}$

${ }^{1}$ Research Center for Psychiatry and Behavioral Sciences, Shiraz University of Medical Sciences, Shiraz, Iran
${ }^{2}$ Health Policy Research Center, Institute of Health, Shiraz University of Medical Sciences, Shiraz, Iran
${ }^{3}$ Department of Psychiatry, Faculty of Medicine, Social Development \& Health Promotion Research Centre, Gonabad University of
Medical Sciences, Gonabad, Iran
${ }^{4}$ Department of Operative Dentistry, School of Dentistry, Tehran University of Medical Sciences, Tehran, Iran
${ }^{5}$ Department of Midwifery, Estahban Branch, Islamic Azad University, Estahban, Iran

Abstract

Background: One unprecedented year after the coronavirus disease 2019 (COVID-19), the pandemic is no longer a short-term stressor; the unremitting/chronic effects of COVID-19 disease is likely to cause impaired physical and mental health upon population and the implemented public health and social measures to limit transmission and reduce mortality and morbidity from COVID-19 expose many people to social isolation, job loss, and economic recession. This study aims to compare mental status and four mental symptoms (somatization, anxiety, depression, and social functions) between two periods during the first year of the COVID-19 pandemic. Materials and Methods: Current study consists of two cross-sectional mental health surveys on the Iranian adult population carried out in two periods of March to April 2020 and December 2020 to February 2021 in two important Provinces of Iran (Fars and Khorasan Razavi). In the first survey, 1337 individuals participated in the study and completed the General Health Questionnaire-28, while in the second survey, 1205 participants completed the same questionnaire. Results: Among 1337 participants of the first survey, there were $876(65.5 \%)$ females and 461 (34.5\%) males with an average age of $37.41 \pm 10.58$ years. In the second survey, there were 1205 participants with mean age of $33.79 \pm 19.57$ years. The rates of females and males were $57.7 \%$ and $42.3 \%$, respectively. Compared to the first survey, the second one showed that poor mental health condition that was 1.40 (95\% confidence interval: $1.17-$ 1.67) times higher based on the age, sex, education, marital status, economic, alcohol, cigarette, water-pipe, and sedative $(\mathrm{P}<0.001)$. Conclusion: Poor mental health status has increased during the first year of the COVID-19 pandemic. These results revealed that the COVID-19 pandemic was a chronic stressor faced by people every day; therefore, more robust mental health-related considerations must be implemented.

[GMJ.2021;10:e2199] DOI:10.31661/gmi.v10i0.2199

Keywords: Mental Health; Coronavirus; Pandemics; Iran

GMJ

Copyright(C) 2021, Galen Medical Journal. This is an open-access article distributed under the terms of the Creative Commons Attribution 4.0 International License (http://creativecommons.org/licenses/by/4.0/) Email:info@gmj.ir $\square$ Correspondence to:

Seyed Taghi Heydari, Health Policy Research Center, Institute of Health, Shiraz University of Medical Sciences, Shiraz, Iran

Telephone Number: +989173034420

Email Address: heydari.st@gmail.com 


\section{Introduction}

A fter one unprecedented year of coronavirus disease 2019 (COVID-19), which was first emerged in Wuhan, China, stats show the impacts of the pandemic on over 85 million confirmed cases all around the world [1]. The growing number of over 79000 currently reported cases and over 15000 deaths in the last 24 hours showed that this public health scenario had not finished yet [1]. As the pandemic wears on, uncertainty and fear would arise; moreover, the community health or social measures applied to constrain COVID-19 prevalence and its mortality rate have some adverse effects, including social isolation, job loss, and economic recession [2]. Currently, the pandemic is no longer a short-term stressor, and its unremitting/ chronic effects are likely to cause impaired physical and mental health [3].

Iran is one of the prominent Middle Eastern developing countries. The first case of COVID-19 was officially declared on February 19,2020 [4], and, at the time of writing, as of January 10, 2021, 1.2 million confirmed cases and 56000 deaths were reported in Iran [1]. The initial governmental public health and social responses to the coronavirus crisis were restrictions on gatherings and traveling, social distancing, stay-at-home, and wearing facial mask orders [5]. Despite all of these actions, the progression and transmission of the virus were beyond the anticipations and forced the government to apply more critical restrictions and controls such as multiple strict lockdowns, complete closures of schools, cultural places, and non-essential businesses, travel ban, and transportation limitations [6]. Now, after months of quarantine, prolonged social isolation and loneliness have become a great global mental health concern that could cause lifespan reduction, higher risks of physical and mental morbidities, and even suicidal ideations, especially in highrisk populations [7]. Before the pandemic, Noorbala et al. [8] had reported the results of a mental health survey that investigated the adult Iranian population through the General Health Questionnaire-28 (GHQ-28). Results showed that the likelihood of mental disorders was determined to $23.4 \%$ among participants, which consisted of $27.6 \%$ of women and $19.3 \%$ of men [8]. Based on our previous mental health survey carried out during March-April 2020, the first months of the COVID-19 outbreak, in one of the largest provinces of Iran, the rate of mental disorders was found two times higher than in other provinces [9]. Findings showed that $46.1 \%$ of participants were suspected of having poor mental health status [9].

Noteworthy results from a meta-analysis of the psychological and mental impact of COVID-19 showed an increase in the prevalence of stress, anxiety, and depression among the general population during the COVID-19 pandemic [10, 11]. As stated in Iran, anxiety [12], depression [13], posttraumatic stress disorder [14], obsessivecompulsive behaviors [15], substance abuse [16], suicidal ideation and attempts, and other symptoms of distress could be induced and/or exacerbated as a result of the various COVID19-related factors such as fear, stress, anxiety, uncertainties, escalating number of mortalities [17], psychological impacts of the pandemic (such as the global economic recession [18]), increase of the prices of essential and healthrelated goods, decrease of the income, job loss [19], and the ongoing effects of sanctions and embargo [6, 20, 21].

Consequently, it was hypothesized that since other similar chronic stresses could induce serious physical, cognitive, and psychological symptoms [2], mental health deterioration was greater than expected; therefore, it would require more forceful measures. The current study evaluated a comparison of the mental health conditions and four major mental symptoms, including somatization, anxiety, depression, and social function during the first year of the COVID-19 pandemic.

\section{Materials and Methods}

The current study was carried out based on two cross-sectional studies that evaluated the mental health among Iranian adults from March to April 2020 (first period) and December 2020 to February 2021 (second period). 
Due to limitations and hazards resulting from face-to-face interactions with the participants, an online questionnaire was applied. Participants were selected randomly from two larg provinces of Iran (Fars and Khorasan Razavi). The link of the questionnaire and online written consent were sent to these random phone numbers. The inclusion criteria were adults with the ability to use smartphones, reading and writing skills. All research participants announced their permission to participate in the study by completing the questionnaires; moreover, the privacy and confidentiality of collected data were ensured. In the first survey carried out from March to April 2020, 1337 participants completed GHQ-28. In the second survey, which was performed from December 2020 to February 2021, there were 1205 participants. GHQ-28 is a valid and reliable scale, which contains 28 questions. It is scored by implementing a Likert scale to evaluate the general mental health status and its main dimensions developed by Goldberg and Hillier (1979) [22, 23]. The validated Persian version was adapted by Noorbala et al.[8]; also, results of data collected from GHQ-28 showed that the proposed cut-off point for poor mental health status was more than 23 , while Cronbach's alpha was determined to be 0.831 [24]. In addition, GHQ-28 assessed four main dimensions of mental health, including anxiety, social function, somatization, and depression. Each dimension contained seven items, and the cuff-off point for poor mental health was more than 10. Self-report questions about the sexuality, age, educational status, marital status, economic status-which contained the income level based on the selfreports of participants regarding their monthly costs-, history of smoking the cigarette and/ or water-pipe, and the abuse of alcohol, sedative, and/or other drugs were included in the questionnaire. The above-mentioned factors were recognized as the main indicators of mental health conditions based on the published literature [25-27].

\section{Ethics Approval and Consent to Participate} This study was approved by the ethics committee of Shiraz University of Medical
Sciences (code: IR.SUMS.REC.1399.077). All the participants were asked to submit their written consent forms to participate in this study before completing the questionnaires. All the participants completed the questionnaires willingly and were ensured of the confidentiality of the collected data.

\section{Statistical Analysis}

The process of data analysis was carried out using a Statistical Package for Social Sciences Version 19.0 (SPSS Inc., Chicago, IL, USA). Univariate and multiple logistic regression were performed to compute the odds ratio (OR) and the corresponding 95\% confidence interval $(95 \% \mathrm{CI})$ of mental health statuses and dimensions based on periods. P-value less than 0.05 was considered to be statistically significant.

\section{Results}

Among 1337 participants of the first survey, there were $876(65.5 \%)$ females and $461(34.5 \%)$ males with the mean age of $37.41 \pm 10.58$ years. The number of individuals who participated in the second survey was 1205. The rates of females and males were 695 $(57.7 \%)$ and $510(42.3 \%)$; also, their mean age was $33.79 \pm 19.57$ years. As represented in Table-1, several factors were statistically significant between the mentioned periods, including age, marital status, educational and income level, and alcohol usage.

Results achieved from the first survey revealed that the likelihood of weak mental conditions, somatization symptoms, distress symptoms, social malfunctions, and depression were $43.8 \%, 6.8 \%, 18.0 \%, 22.5 \%$, and $4.8 \%$, respectively. Furthermore, the findings of the second survey showed that the ratios of all of the above-mentioned factors were $51.6 \%$, $9.6 \%, 18.3 \%, 26.5 \%, 7.1 \%$, respectively.

Based on the univariate logistic regression analysis, the poor mental health status of the second survey was higher than the first one $(\mathrm{OR}=1.37,95 \% \mathrm{CI}: 1.17-1.60 ; \mathrm{P}=0.01)$. Also, the somatization, social malfunction, and depression were increased in the second period $(\mathrm{P}<0.05)$. However, there was not any considerable change in the anxiety of both 
Table 1. Demographic Characteristics Between Two Time Periods

\begin{tabular}{|c|c|c|c|c|}
\hline Variables & Category & $\begin{array}{c}\text { First period } \\
\text { n }(\%) \\
\end{array}$ & $\begin{array}{c}\text { Second period } \\
\text { n }(\%)\end{array}$ & P-value \\
\hline \multirow{2}{*}{ Sex } & Male & $461(34.5)$ & $510(42.3)$ & \multirow{2}{*}{$<0.001$} \\
\hline & Female & $876(65.5)$ & $695(57.7)$ & \\
\hline \multirow{2}{*}{ Marital status } & Single & $371(27.7)$ & $615(51)$ & \multirow{2}{*}{$<0.001$} \\
\hline & Married & $966(72.3)$ & $590(49)$ & \\
\hline \multirow{5}{*}{ Education level } & Under diploma & $98(7.3)$ & $147(12.2)$ & \multirow{5}{*}{$<0.001$} \\
\hline & Diploma & $273(20.4)$ & $368(30.5)$ & \\
\hline & Associate degree & $68(5.1)$ & $29(2.4)$ & \\
\hline & Bachelor & $570(42.6)$ & $576(47.8)$ & \\
\hline & Master degree or higher & $328(24.5)$ & $85(7.1)$ & \\
\hline \multirow{3}{*}{ Income level } & Lower income & $282(21.1)$ & $254(21.1)$ & \multirow{3}{*}{$<0.001$} \\
\hline & Sufficient & $668(50)$ & $448(37.2)$ & \\
\hline & Higher income & $387(28.9)$ & $503(41.7)$ & \\
\hline \multirow{2}{*}{ Cigarette } & Yes & $174(13)$ & $190(15.8)$ & \multirow{2}{*}{$<0.001$} \\
\hline & No & $1161(87)$ & $1015(84.2)$ & \\
\hline \multirow{2}{*}{ Water-pipe } & Yes & $167(12.5)$ & $220(18.3)$ & \multirow{2}{*}{$<0.001$} \\
\hline & No & $1169(87.5)$ & $985(81.7)$ & \\
\hline \multirow{2}{*}{ Alcohol } & Yes & 197 (14.8) & $231(19.2)$ & \multirow{2}{*}{$<0.001$} \\
\hline & No & $1138(85.2)$ & $974(80.8)$ & \\
\hline \multirow{2}{*}{ Sedatives } & Yes & $247(18.5)$ & $155(12.9)$ & \multirow{2}{*}{$<0.001$} \\
\hline & & $1087(81.5)$ & $1050(87.1)$ & \\
\hline Age,y $($ mean \pm SD) & & $37.41 \pm 10.58$ & $33.79 \pm 19.57$ & $<0.001$ \\
\hline
\end{tabular}

surveys $(\mathrm{P}=0.799)$. Considering the important factors of age, sex, education, marital status, economic, alcohol, cigarette, water-pipe, and sedative, the poor mental health condition was $1.40 \quad(95 \% \quad \mathrm{CI}: \quad 1.17-1.67 ; \quad \mathrm{P}<0.001)$ times higher in the second survey compared to the first one $(\mathrm{P}<0.001)$. Somatization and depression were also increased by $1.76(95 \%$ CI: $1.29-2.41 ; \mathrm{P}<0.001)$ and $1.66(95 \% \mathrm{CI}$ : $1.14-2.42 ; \mathrm{P}=0.009$ ), respectively. However, anxiety and social malfunction were not significantly changed in both surveys $(\mathrm{P}>0.05$, Table-2).

\section{Discussion}

It has been one year since the first detection of coronavirus symptoms in Wuhan, China. However, enough attention has not been paid to the change of mental health conditions since the beginning of the pandemic [28]. It could be found from the current study that the mental health conditions of Iranians have worsened from the first period to the second period. Three mental health-related subscales, including the somatization, anxiety, and depression symptoms were also exacerbated between these two periods, while the social function was ameliorated. Reports achieved from 2003 Coronavirus SARS, which was a serious acute respiratory syndrome, outbreak indicated long-term dramatic psychosocial effects especially on survivors and health care workers $[29,30]$ such as fear, loneliness, boredom, anger, and stress-related mental disorders like generalized anxiety disorder and major depression [31-33]. Consequently, a global concern regarding mental health has arisen, and preparation for an integral mental health-related response to the future similar pandemics such as the ongoing COVID-19 pandemic seemed to be critical [34]. 
Table 2. The Comparison of Mental Symptoms Severity and Dimensions in COVID-19 Pandemic by Logistic Regression

\begin{tabular}{|c|c|c|c|c|c|c|c|}
\hline & Variables & $\begin{array}{c}\text { No } \\
\text { n }(\%)\end{array}$ & $\begin{array}{c}\text { Yes } \\
\text { n }(\%)\end{array}$ & $\begin{array}{l}\text { Unadjusted odds } \\
\text { ratio }(95 \% \text { CI })\end{array}$ & P-value & $\begin{array}{c}\text { Adjusted } \\
\text { odds ratio } \\
(95 \% \text { CI) }\end{array}$ & P-value \\
\hline \multicolumn{8}{|c|}{ Mental disorders } \\
\hline \multirow{2}{*}{$\stackrel{\mathscr{E}}{\Xi}$} & First period & $752(56.2)$ & $585(43.8)$ & 1 & - & 1 & - \\
\hline & Second period & $583(48.4)$ & $622(51.6)$ & $1.37(1.17$ to 1.6$)$ & $<0.001$ & $\begin{array}{c}1.4(1.17 \text { to } \\
1.67)\end{array}$ & $<0.001$ \\
\hline \multicolumn{8}{|c|}{ Somatization } \\
\hline \multirow{2}{*}{$\stackrel{\mathscr{\Xi}}{\Xi}$} & First period & $\begin{array}{l}1246 \\
(93.2)\end{array}$ & $91(6.8)$ & 1 & - & 1 & - \\
\hline & Second period & $\begin{array}{c}1089 \\
(90.4)\end{array}$ & $116(9.6)$ & $1.46(1.1$ to 1.94$)$ & 0.01 & $\begin{array}{c}1.76(1.29 \text { to } \\
2.41)\end{array}$ & $<0.001$ \\
\hline \multicolumn{8}{|c|}{ Anxiety } \\
\hline \multirow{2}{*}{$\stackrel{\mathscr{E}}{\Xi}$} & First period & $1097(82)$ & $240(18)$ & 1 & - & 1 & - \\
\hline & Second period & $984(81.7)$ & $221(18.3)$ & $1.03(0.84$ to 1.26$)$ & 0.799 & $\begin{array}{c}1.13(0.9 \text { to } \\
1.42)\end{array}$ & 0.278 \\
\hline \multicolumn{8}{|c|}{ Social function } \\
\hline \multirow{2}{*}{$\stackrel{\mathscr{\Xi}}{\Xi}$} & First period & $\begin{array}{l}1036 \\
(77.5)\end{array}$ & $301(22.5)$ & 1 & - & 1 & - \\
\hline & Second period & $886(73.5)$ & $319(26.5)$ & $1.24(1.03$ to 1.49$)$ & 0.02 & $\begin{array}{c}1.16(0.95 \text { to } \\
1.41)\end{array}$ & 0.148 \\
\hline \multicolumn{8}{|c|}{ Depression } \\
\hline \multirow{2}{*}{$\stackrel{\mathscr{E}}{.}$} & First period & $\begin{array}{l}1273 \\
(95.2)\end{array}$ & $64(4.8)$ & 1 & $<0.001$ & 1 & - \\
\hline & Second period & $\begin{array}{l}1120 \\
(92.9)\end{array}$ & $85(7.1)$ & $1.51(1.08$ to 2.11$)$ & - & $\begin{array}{c}1.66(1.14 \text { to } \\
2.42)\end{array}$ & 0.009 \\
\hline
\end{tabular}

$\mathrm{Cl}$ : Confidence interval, Adjusted by age, sex, education, marital status, economic, alcohol, cigarette, water-pipe, and sedative

One year after the COVID-19 outbreak, the pandemic has changed into a chronic stressor with emerging adverse effects [2]. The previous national mental health surveys on the adult population in 2015 carried out in Iran showed that the likelihood of mental disorders was higher among $23.4 \%$ of the cases [8, 35, 36]. Findings revealed that the Iranian mental health conditions were exacerbating during the pandemic, which is in line with most previous studies $[7,9,16]$.

\section{Depression}

The government imposed nationwide restrictive rules from November to December 2020. A two-week closure of non-essential services, workplaces, and businesses was also applied due to the escalating number of COVID-19 patients, subsequent rise in mortality, and shortage of intensive care unit beds. Commuting into and out of the cities were forbidden, and intra-city transportations were also banned from early night to early morning to avoid the night gatherings. Feelings of loneliness, social detachment, boredom, and restriction of freedom were other concerns in addition to the grief resulting from morbidity and mortality of relatives and sorrowful news [37-39]. These were the notable factors that played a vital role in the exacerbation of mental health conditions from March to December 2020.

\section{Somatization}

The aggravation of somatization during the pandemic was another remarkable finding, 
which could be compared with results achieved from previous mental health surveys during pandemics $[16,30,32,40]$. COVID-19 is a disease with a wide range of symptoms; moreover, the incubation period could range from days to weeks, and 30 to $40 \%$ of the infections are asymptomatic [41, 42]. After one year, the disease characteristics, as well as uncertainties about the natural history, disease course, and treatment, could be transformed into chronic unremitting stress and induce everlasting anxiety, irresistible fear of contagion, sense of uncertainty about physical health status, and psychosomatic symptoms [2, 43].

\section{Anxiety and Social Function}

Furthermore, social function and anxiety symptoms did not significantly change from the first to the second period. Results showed that despite the existence of knowledge about the virus, multiple mental health tips, and advice of specialized public health agencies [44], COVID-19 is still recognized as a predominant stressor, and people all around the world are still dealing with the pandemic and its complications. However, it is believed that the mentioned knowledge in addition to the advancement of various online facilities and infrastructures, including distance learning, online shopping, telehealth, and telecommunication could gradually relieve the degree of anxiety in general population and ameliorate the social function [45].

\section{Limitations}

The first limitation of this study was mainly due to the restricted access to the respondents, such as the limitation in conducting face-toface interviews due to the pandemic. Second, there was a lack of essential data such as the previous medical history, drug history, etc. Hence, we recommend considering these parameters in future studies.

\section{Conclusion}

The current study reported an increase in the general population's psychological symptoms of somatization and depression during the first year of the COVID-19 pandemic. These results also revealed that currently, the COVID-19 pandemic is a chronic everyday stressor, and more robust considerations about mental health conditions are highly required.

\section{Acknowledgments}

This study was supported by a grant from the Vice-chancellor for Research, Shiraz University of Medical Sciences, Shiraz, Iran (grant Number: 22143). Funding the body of the study did not play any role in the design of the study, collection, analysis, interpretation of data, and writing the manuscript.

\section{Conflict of Interest}

The authors declare that they have no competing interests.

\section{References}

1. World Health Organization. WHO Coronavirus Disease (COVID-19) Dashboard. https://covid19.who.int/. Accessed 1/10/2021. 2020.

2. Marin MF, Lord C, Andrews J, Juster RP, Sindi S, Arsenault-Lapierre G, et al. Chronic stress, cognitive functioning and mental health. Neurobiol Learn Mem. 2011;96(4):583-95.

3. Mohr C, Braun S, Bridler R, Chmetz F, Delfino JP, Kluckner VJ, et al. Insufficient coping behavior under chronic stress and vulnerability to psychiatric disorders. Psychopathology. 2014;47(4):235-43.

4. Ghadir MR, Ebrazeh A, Khodadadi J, Zamanlu M, Shams S, Nasiri M, et al. The COVID-19 Outbreak in Iran; The First Patient with a Definite Diagnosis. Arch Iran Med. 2020;23(7):503-4.

5. Salimi R, Gomar R, Heshmati B. The COVID-19 outbreak in Iran. J Glob Health. 2020;10(1).

6. Venkatesan P. COVID-19 in Iran: round 2. Lancet Infect Dis. 2020;20(7):784-.

7. Xiong J, Lipsitz O, Nasri F, Lui 
LMW, Gill H, Phan L, et al. Impact of COVID-19 pandemic on mental health in the general population: A systematic review. J Affect Disord. 2020;277:55-64.

8. Noorbala AA, Bagheri Yazdi SA, Faghihzadeh S, Kamali K, Faghihzadeh E, Hajebi A, et al. Trends of Mental Health Status in Iranian Population Aged 15 and above between 1999 and 2015.

Arch Iran Med. 2017;20(11 Suppl. 1):S2s6.

9. Mani A, Estedlal AR, Kamali M, Ghaemi SZ, Zarei L, Shokrpour N, et al. Mental health status during COVID-19 pandemic in Fars Province, Iran: timely measures. BMC Public Health. 2020;20(1):1866.

10. Salari N, Hosseinian-Far A, Jalali R, Vaisi-Raygani A, Rasoulpoor S, Mohammadi M, et al. Prevalence of stress, anxiety, depression among the general population during the COVID-19 pandemic: a systematic review and metaanalysis. Global Health. 2020;16(1):57.

11. Luo M, Guo L, Yu M, Jiang W, Wang H. The psychological and mental impact of coronavirus disease 2019 (COVID-19) on medical staff and general public - A systematic review and meta-analysis. Psychiatry Res. 2020;291:113190.

12. McEwen BS, Eiland L, Hunter RG, Miller MM. Stress and anxiety: structural plasticity and epigenetic regulation as a consequence of stress. Neuropharmacology. 2012;62(1):3-12.

13. Hammen C, Kim EY, Eberhart NK, Brennan PA. Chronic and acute stress and the prediction of major depression in women. Depress Anxiety. 2009;26(8):718-23.

14. Tang W, Hu T, Hu B, Jin C, Wang G, Xie C, et al. Prevalence and correlates of PTSD and depressive symptoms one month after the outbreak of the COVID-19 epidemic in a sample of home-quarantined Chinese university students. J Affect Disord. 2020;274:1-7.

15. Banerjee D. The other side of COVID-19: Impact on obsessive compulsive disorder (OCD) and hoarding. Psychiatry Res. 2020;288:112966.
16. Brenner MH, Bhugra D. Acceleration of Anxiety, Depression, and Suicide:

Secondary Effects of Economic Disruption Related to COVID-19. Front Psychiatry. 2020;11:592467.

17. Koffman J, Gross J, Etkind SN, Selman L. Uncertainty and COVID-19: how are we to respond? J R Soc Med. 2020;113(6):211-6.

18. Nicola M, Alsafi Z, Sohrabi C, Kerwan A, Al-Jabir A, Iosifidis C, et al. The socio-economic implications of the coronavirus pandemic (COVID-19): A review. Int J Surg. 2020;78:185-93.

19. Mousavi SA-M, Hooshyari Z, Ahmadi A. The Most Stressful Events during the COVID-19 Epidemic. Iran J Psychiatry. 2020;15(3):220-7.

20. Murphy A, Abdi Z, Harirchi I, McKee M, Ahmadnezhad E. Economic sanctions and Iran's capacity to respond to COVID-19. Lancet Public Health. 2020;5(5):e254.

21. Takian A, Raoofi A, KazempourArdebili S. COVID-19 battle during the toughest sanctions against Iran. Lancet. 2020;395(10229):1035-6.

22. Goldberg DP, Gater R, Sartorius N, Ustun TB, Piccinelli M, Gureje O, et al. The validity of two versions of the GHQ in the WHO study of mental illness in general health care. Psychol Med. 1997;27(1):191-7.

23. Goldberg DP, Hillier VF. A scaled version of the General Health Questionnaire. Psychol Med. 1979;9(1):139-45.

24. Noorbala A, Mohammad K, Bagheri Yazdi S. Validation of GHQ-28 in Iran. Hakim. 1999;5:101-10.

25. Alegría $M$, NeMoyer $A$, Falgàs Bagué $I$, Wang Y, Alvarez K. Social Determinants of Mental Health: Where We Are and Where We Need to Go. Curr Psychiatry Rep. 2018;20(11):95.

26. Torrens M, Gilchrist G, DomingoSalvany A. Psychiatric comorbidity in illicit drug users: Substance-induced versus independent disorders. Drug Alcohol Depend. 2011;113(2-3):147-56.

27. Twomey CD, Baldwin DS, Hopfe M, Cieza A. A systematic review of the 
predictors of health service utilisation by adults with mental disorders in the UK. BMJ Open. 2015;5(7).

28. Naughton F, Ward E, Khondoker M, Belderson P, Marie Minihane A, Dainty $\mathrm{J}$, et al. Health behaviour change during the UK COVID-19 lockdown: Findings from the first wave of the C-19 health behaviour and well-being daily tracker study. Br J Health Psychol. 2021;26(2):624-643.

29. Lee AM, Wong JG, McAlonan GM, Cheung V, Cheung C, Sham PC, et al. Stress and psychological distress among SARS survivors 1 year after the outbreak. Canadian journal of psychiatry Can J Psychiatry. 2007;52(4):233-40.

30. Verma S, Mythily S, Chan YH, Deslypere JP, Teo EK, Chong SA. Post-SARS psychological morbidity and stigma among general practitioners and traditional Chinese medicine practitioners in Singapore. Ann Acad Med Singap. 2004;33(6):743-8.

31. Liu X, Kakade M, Fuller CJ, Fan B, Fang Y, Kong J, et al. Depression after exposure to stressful events: lessons learned from the severe acute respiratory syndrome epidemic. Compr Psychiatry. 2012;53(1):15-23.

32. Sim K, Chua HC. The psychological impact of SARS: a matter of heart and mind. CMAJ. 2004;170(5):811.

33. Nickell LA, Crighton EJ, Tracy CS, Al-Enazy H, Bolaji Y, Hanjrah S, et al. Psychosocial effects of SARS on hospital staff: survey of a large tertiary care institution. CMAJ. 2004;170(5):793-8.

34. Douglas PK, Douglas DB, Harrigan DC, Douglas KM. Preparing for pandemic influenza and its aftermath: mental health issues considered. Int J Emerg Ment Health. 2009;11(3):137-44.

35. Noorbala AA, Yazdi SAB, Faghihzadeh S, Kamali K, Faghihzadeh E, Hajebi A, et al. A Survey on Mental Health Status of Adult Population Aged 15 and above in the Province of South Khorasan, Iran. Arch Iran Med. 2017;20(13):S111-S4.

36. Noorbala AA, Yazdi SAB, Faghihzadeh S, Kamali K, Faghihzadeh E, Hajebi A, et al. A survey on mental health status of adult population aged 15 and above in the province of North Khorasan, Iran. Arch Iran Med. 2017;20(13):S87-S90.

37. Bozdağ F. The psychological effects of staying home due to the COVID-19 pandemic. J Gen Psychol. 2021;148(3):226-248.

38. Brooks SK, Webster RK, Smith LE, Woodland L, Wessely S, Greenberg $\mathrm{N}$, et al. The psychological impact of quarantine and how to reduce it: rapid review of the evidence. Lancet. 2020;395(10227):912-20.

39. Brodeur A, Clark AE, Fleche S, Powdthavee N. COVID-19, lockdowns and well-being: Evidence from Google Trends. J Public Econ. 2021;193:104346.

40. Pierce M, Hope H, Ford T, Hatch S, Hotopf M, John A, Kontopantelis E, Webb R, Wessely S, McManus S, Abel KM. Mental health before and during the COVID-19 pandemic: a longitudinal probability sample survey of the UK population. Lancet Psychiatry. 2020;7(10):883-892.

41. Guan W-j, Ni Z-y, Hu Y, Liang W-h, Ou C-q, He J-x, et al. Clinical characteristics of coronavirus disease 2019 in China. $\mathrm{N}$ Engl J Med. 2020;382(18):1708-20.

42. Oran DP, Topol EJ. Prevalence of Asymptomatic SARS-CoV-2 Infection: A Narrative Review. Ann Intern Med. 2020;173(5):362-367.

43. Chaturvedi SK. Health anxiety, healthrelated life events, and somatization during COVID-19 pandemic can increase chronic pain. Pain. 2020;161(11):2652.

44. Duan L, Zhu G. Psychological interventions for people affected by the COVID-19 epidemic. Lancet Psychiatry. 2020;7(4):300-2.

45. Wijesooriya NR, Mishra V, Brand PLP, Rubin BK. COVID-19 and telehealth, education, and research adaptations. Paediatr Respir Rev. 2020;35:38-42. 